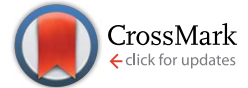

Cite this: RSC Adv., 2017, 7, 5322

Received 3rd October 2016 Accepted 5th December 2016

DOI: $10.1039 / c 6 r a 24689 c$

www.rsc.org/advances

\title{
High fat diet induces alterations to intraepithelial lymphocyte and cytokine mRNA in the small intestine of C57BL/6 mice
}

\author{
Franco Robles E., ${ }^{a}$ Pérez Vázquez V., ${ }^{a}$ Ramírez Emiliano J., ${ }^{a}$ González Amaro R. ${ }^{b}$ \\ and López Briones S. *c
}

\begin{abstract}
The aim of this work was to investigate the possible effect of high fat diet (HFD) induced obesity on ilEL subsets and their cytokine mRNA levels in C57BL/6 mice. Two groups of C57BL/6 mice were kept in separate cages and fed with either a normal diet (control) or HFD. After 12 weeks of treatment the ilELs were isolated and analyzed by FACS. Additionally, the mRNA levels of IL-2, IL-15, TGF- $\beta$, TNF- $\alpha$, IFN- $\gamma$ granzyme $B$ and perforin were quantified by RT-PCR. We found that HFD induced a proportional shift in $\mathrm{TCR} \gamma \delta^{+}$and $\mathrm{TCR} \alpha \beta^{+}$composition within the ilEL population. Also, a significant increase in the mRNA levels of TNF- $\alpha$, perforin and granzyme B was detected on ilELs from HFD mice. Our findings may provide important insights into intestinal changes associated to HFD induced obesity, which could eventually lead to intestinal inflammation. However, further investigations are required to elucidate the molecular mechanism of HFD induced changes on ilELs.
\end{abstract}

\section{Introduction}

Worldwide, obesity is one of the most important public health problems. It has been described as a chronic degenerative disease, produced by an imbalance between intake and energy consumption, with contribution of environmental and genetic factors. ${ }^{\mathbf{1 2}}$ Obesity is associated with type 2 diabetes mellitus, enhanced cardiovascular risk, fatty liver, and others metabolic alterations..$^{3-5}$ Moreover, obesity is strongly linked to chronic low grade systemic inflammation, characterized by increased levels of IL-6, TNF- $\alpha$ and acute phase proteins. ${ }^{6-8}$ Although the mechanisms underlying the inflammation associated with obesity have not been entirely elucidated, it is well known that adipose tissue is an important source of pro-inflammatory cytokines. ${ }^{9}$ In addition, biological pro inflammatory mechanisms in gut could also contribute to this phenomenon. ${ }^{\mathbf{1 0 , 1 1}}$

On the other hand, intestinal intraepithelial lymphocytes (iIELs) are an essential mechanism of cellular defense against pathogenic microorganisms. The iIELs have also important immunoregulatory functions, and a potent cytolitic activity. ${ }^{\mathbf{1 2 - 1 5}}$ In mice, similar proportions of TCR $\alpha \beta$ and TCR $\gamma \delta$ expressing

${ }^{a}$ Departamento de Ciencias Médicas, División de Ciencias de la Salud, Campus León, Universidad de Guanajuato, Mexico

${ }^{b}$ Departamento de Inmunología, Escuela de Medicina, Universidad Autónoma de San Luís Potosí, San Luís Potosí, Mexico

'Departamento de Medicina y Nutrición, División de Ciencias de la Salud, Campus León-Edificio de Laboratorios, Universidad de Guanajuato, Blvd. Puente Milenio \#1001, Fracción del Predio San Carlos, León, Gto., Mexico, 37670. E-mail: lobris@ yahoo.com; Tel: +524772674900
iIELs have been identified in the intestinal compartment, most of these cells are expressing the homodimer CD8 $\alpha \alpha$, which has not been detected on other tissues. ${ }^{16-19}$ Likewise, CD4 ${ }^{-} \mathrm{CD} 8^{-}$ double negative lymphocytes reside in the small intestine. ${ }^{20}$ Furthermore, $\mathrm{CD} 4^{+}$lymphocytes are a minor subset in the iIELs compartment, and some of these cells are $\mathrm{CD} 4^{+} \mathrm{CD} 8^{+}$double positive. ${ }^{21,22}$ In addition, iIELs include thymus-dependent cells such as TCR $\alpha \beta^{+} \mathrm{CD} 8 \alpha \beta^{+}$, as well as thymus-independent cells; such as both TCR $\alpha \beta^{+} \mathrm{CD} 8 \alpha \alpha^{+}$and TCR $\gamma \delta^{+} \mathrm{CD} 8 \alpha \alpha^{+} .^{23-25}$

iIELs may regulate intestinal functions by producing cytokines, which control intestinal homeostasis and injury. Under pathological environment, iIELs cytokine expression is altered, and these changes could mediate functional modifications in the small intestine. iIELs secrete mainly IFN- $\gamma$, TNF- $\alpha$, IL-2, TGF- $\beta$, IL15 and others. This way, cytokines produced by iIELs are an important way to modulate the local intestinal immune response, as well as keep the integrity of the intestinal barrier. ${ }^{26}$

iIELs development is dependent of different factors, including intestinal microbiota, ${ }^{27,28}$ specific TCR engagement, ${ }^{29,30}$ and vitamin D. ${ }^{31}$ On the other hand, it has been reported that high fat diet (HFD) is associated with important changes in gut microbiota, triggering an inflammatory response; ${ }^{11,32}$ however, the possible changes on the iIELs subsets have not been explored on HFD induced obesity mice model. Herein, the effect of HFD on iIELs subsets, as well as mRNA cytokines levels in C57BL/6 mice was determined. We found that HFD induced significant changes in iIEL subsets, together with an increase on mRNA levels of TNF- $\alpha$, perforin, and granzyme-B. Our data suggest that HFD lead to disrupt the intestinal homeostasis, producing changes on iIELs 
proportions and increasing mRNA levels of TNF- $\alpha$, perforin, granzyme-B. Thus, HFD induced intestinal changes may contribute to trigger the inflammation linked to obesity.

\section{Material and methods}

\section{Mice and antibodies}

Five to seven week old C57BL/6NHsd male mice were purchased from Harlan Mexico, S.A. de C.V. (México, D.F.). Mice were maintained in a pathogen-free environment, under standard room conditions of temperature, humidity and free access to food and water. The mice were maintained in accordance with to the official Mexican guidelines for the use and care of experimental animals, and the protocol was approved by the ethics committee of the Department of Medical Sciences of Universidad de Guanajuato, México.

The following monoclonal antibodies were used for iIELs staining and FACS analysis: FITC-anti-CD $8 \beta$, PE-anti-TCR $\gamma \delta$, PerCP-anti-CD8 $\alpha$, APC-anti-TCR $\beta$, PerCP-anti-CD4, and purified anti-Fc $\gamma$ receptor (CD16/CD32.). All anti mouse monoclonal antibodies were purchased from BD Biosciences (San Diego, CA), and diluted 1:10 in FACS buffer (PBS, FBS 5\%, and sodium azide $0.05 \%$ ) before use them.

\section{Diet intervention}

Two groups of mice ( $n=10$ each group) were kept in separate cages. One of these designated as a control, fed with a normal diet $(2014 \mathrm{~S}$ Teklad Global 14\% protein rodent maintenance diet, $4 \%$ fat); whereas another group was fed with a high fat diet for 12 weeks (TD.06414, adjusted calories diet: $60 \mathrm{kcal} / \mathrm{fat}$, $34.3 \%$ fat, $27.3 \%$ protein). According to the diet manufacturer, the approximate fatty acid profile (\% of total fat) is the following: $37 \%$ saturated, $47 \%$ monounsaturated, $16 \%$ polyunsaturated. Both diets were purchased from Harlan Mexico S.A. de C.V. After 12 weeks, mice were sacrificed and the small intestine was removed to isolate and purified the iIELs.

\section{Body weight gain and glucose, cholesterol, and triglyceride serum levels measurement}

The weight gain of each mouse was assessed with an analytical balance and recorded every 7 days until the end of the experiment. Blood samples were obtained from the retro-ocular plexus with a capillary microtube and immediately used for glucose, cholesterol and triglyceride determinations, with an Accutrend GCT system (according to the manufacturer's instructions). After that, mice were sacrificed by cervical dislocation and small intestine was collected in cold PBS.

\section{iIELs purification and staining}

iIELs were isolated from the small intestine as previously described. ${ }^{33}$ Briefly, Peyer's patches were identified and removed. After flushing with $50 \mathrm{~mL}$ of PBS $\left(4^{\circ} \mathrm{C}\right)$, gut was opened on a wet linen square. The mucosa was scraped with a scalpel and then dissociated by stirring for $20 \mathrm{~min}$ at room temperature in $50 \mathrm{~mL}$ of RPMI 1640 containing 10\% heat inactivated FBS plus $1 \mathrm{mM}$ dithioerythritol (Sigma Chemical Co., St. Louis, MO) and $1 \mathrm{mM}$
EDTA. After centrifugation at $1500 \mathrm{rpm}$ for $10 \mathrm{~min}$, the cell pellet was resuspended in RPMI 1640 and passed through a glass wool column prewashed with RPMI 1640 containing 5 mM HEPES. The suspension obtained was then centrifuged and the pellet used to purify iIELs by centrifugation through a discontinuous Percoll (Amersham Pharmacia Biotech, Piscataway, NJ) gradient. Cells were resuspended in a $72 \%$ Percoll/PBS solution, overlayed with an equal volume of $36 \%$ Percoll/PBS and centrifuged at 2000 $\times g$ for $30 \mathrm{~min}$ at room temperature. Then, cells at the interface (iIELs) were, washed and incubated with anti-CD16/CD32 to block nonspecific mAb binding. Cells were then immunostained with different combinations of the indicated mAbs. Four-color multiparameter immunofluorescence staining was analyzed in a FACSCalibur flow cytometer (Becton Dickinson, San Jose, CA). iIELs were gated using forward and side scatter to exclude dead cells, and the data were analyzed using the Cell Quest software (Becton Dickinson, San Jose, CA).

\section{Measurement of cytokine mRNA levels by RT-PCR}

Total mRNA was isolated from iIELs using the RNeasy Mini Kit (QIAGEN, Valencia CA), each RNA sample (2 ng) was reversetranscribed with $50 \mu \mathrm{M}$ of oligo(dT) $)_{20}, 10 \mathrm{mM}$ dNTP mix, $0.1 \mathrm{M}$ DTT, and $15 \mathrm{U}^{-1}$ of ThermoScript ${ }^{\mathrm{TM}}$ RT-PCR system (Invitrogen, Alameda CA) in a volume of $20 \mu \mathrm{L}$ at $42{ }^{\circ} \mathrm{C}$ for $60 \mathrm{~min}$ for synthesis of first-strand cDNA. The PCR amplification was processed in a Perkin Elmer Thermo Cycler 9700 as described above. The PCR products were subjected to electrophoresis in 1.8\% agarose gels, stained with ethidium bromide and visualized under UV light. The specific oligonucleotide primers used in PCR amplification were as follows: IL-2 sense, $5^{\prime}$-TGA TGG ACC TAC AGG AGC TCC TGA G-3'; IL-2 antisense, 5'-GAG TCA AAT CCA GAA CAT GCC GCA G-3'; IL-15 sense, $5^{\prime}$-GGA AGG CTG AGT TCC ACA TC-3'; IL-15 antisense, $5^{\prime}$-AGG GAG ACC TAC ACT GAC AC-3'; IFN- $\gamma$ sense, $5^{\prime}$-AGC GGC TGA CTG AAC TCA GAT TGT AGC TTG TAC CTT TAC TTC ACT G-3'; IFN- $\gamma$ antisense, $5^{\prime}$-GTC ACA GTT TTC AGC TGT ATAGGG-3' ${ }^{\prime}$; TNF- $\alpha$ sense, $5^{\prime}$-GGC AGG TCT ACT TTG GAG TCA TTG C-3'; TNF- $\alpha$ antisense, $5^{\prime}$-ACA TTC GAG GCT CCA GTG AAT TCG G-3' ${ }^{\prime}$; TGF- $\beta$ sense, $5^{\prime}$-TGG ACC GCA ACA ACG CCA TCT ATG- ${ }^{\prime}$; TGF- $\beta$ sense, $5^{\prime}$-TGG AGC TGA AGC AAT AGT TGG TAT CC-3' ${ }^{\prime}$; granzyme B sense, $5^{\prime}$-GCC CAC AAC ATC AAA GAA CAG-3' ${ }^{\prime}$; granzyme B antisense, $5^{\prime}$-AAC CAG CCA CAT AGC ACA CAT- $3^{\prime}$; perforin sense, $5^{\prime}$-GTC ACG TCG AAG TAC TTG GTG$3^{\prime}$; perforin antisense, $5^{\prime}$-ATG GCT GAT AGC CTG TCT CAG- $3^{\prime} ; \beta$ actin sense, $5^{\prime}$-TGG, AAT CCT GTG GCA TCC ATG AAA C- $3^{\prime} ; \beta$ actin antisense, $5^{\prime}$-TAA AAC GCA GCT CAG TAA CAG TCC G-3'. The $\beta$-actin was used as internal control.

Additionally, quantitative real-time polymerase chain reactions (qRT-PCR) were performed using SYBR Green PCR master mix (Applied Biosystems, Foster City, CA) on a StepOnePlus realtime PCR system (Applied Biosystems) following standard procedures. Briefly, cDNA was synthesized from $1 \mu \mathrm{g}$ of total RNA using High cDNA Reverse Transcription Kit (Applied Biosystems). For PCR reactions, $1 \mu \mathrm{L}$ of cDNA template, $0.3 \mu \mathrm{L}$ of forward and reverse primers for specific cytokine $\left(10 \mu \mathrm{mol} \mathrm{L}{ }^{-1}\right.$ each), $10 \mu \mathrm{L}$ of SYBR Green PCR Master Mix, and 8.4 $\mu \mathrm{L}$ of water were added to a final volume of $20 \mu \mathrm{L}$. Thermal cycling was 
performed as follows: $95{ }^{\circ} \mathrm{C}$ for 3 minutes as initial denaturing, followed by 40 cycles of $94{ }^{\circ} \mathrm{C}$ for 30 seconds, $60{ }^{\circ} \mathrm{C}$ for 30 seconds, and a final extension at $72{ }^{\circ} \mathrm{C}$ for 2 minutes. Threshold cycles $\left(C_{\mathrm{T}}\right.$ values) were determined using the StepOne software (Applied Biosystems). Real-time PCR results were normalized using $\beta$-actin as an internal control. Relative mRNA levels were calculated from the $C_{\mathrm{T}}$ values for each sample.

\section{Results}

Effect of HFD on body weight and plasma triglycerides

After 12 weeks of treatment the body weight of HFD mice increased from $20.6 \pm 2.4$ to $42 \pm 3.7 \mathrm{~g}$, while a slight increase of body weight was observed in mice feed with normal diet (Fig. 1a). In addition, although serum levels of glucose and cholesterol were similar in both groups (Fig. 1b and c), a significant increase on triglycerides was detected in HFD mice (Fig. 1d).

\section{Effect of HFD on TCR $\gamma \delta$ iIELs}

We found that HFD induced a significant increase on the proportion of TCR $\gamma \delta$ iIELs (from $47 \pm 3$ to $67 \pm 7 \%, p<0.05$, Fig. $2 \mathrm{a}$ and b). Accordingly, a significant decrease on the proportion of TCR $\alpha \beta$ iIELs was detected in HFD mice (from 44 \pm 4 to $23 \pm 5 \%, p<0.0 .5$, Fig. 2). In contrast, no significant changes on percentage of both TCR $\gamma \delta$ and TCR $\alpha \beta$ iIELs were observed in control mice (Fig. 2a and b).

\section{HFD had not effect on iIELs expressing CD4, CD8 $\alpha \beta$ or CD8 $\alpha \alpha$}

Additional flow cytometry analysis showed that TCR $\alpha \beta^{+} \mathrm{CD} 4^{+}$ cells were not affected by HFD, from $4.4 \pm 0.8 \%$ in control to 4.3 $\pm 1.0 \%$ in HFD mice (Fig. 3a). Likewise, the proportions of both CD $8 \alpha \beta^{+}$and CD $8 \alpha \alpha$ subsets gated on TCR $\alpha \beta^{+}$iIELs were similar in HFD and control mice at the beginning and after 12 weeks of HFD. The percentage of iIELs expressing TCR $\alpha \beta^{+} \mathrm{CD} 8 \alpha \beta^{+}$was 31 $\pm 1.9 \%$ in control and $34 \pm 2 \%$ in HFD mice; while the percentage of iIELs expressing TCR $\alpha \beta^{+} \mathrm{CD} 8 \alpha \alpha^{+}$was $55 \pm 4 \%$ in control and $48 \pm 4 \%$, in HFD mice, respectively (Fig. 3b). Similarly, no significant changes were observed in TCR $\gamma \delta$ lymphocytes expressing CD8 $\alpha \alpha$ or CD8 $\alpha \beta$ in either HFD or control mice. The percentage of iIELs expressing TCR $\gamma \delta^{+} \mathrm{CD} 8 \alpha \alpha^{+}$was $88 \pm 5 \%$ in control and $85 \pm 3 \%$ in HFD mice; while the percentage of iIELs expressing TCR $\gamma \delta^{+} \mathrm{CD} 8 \alpha \beta$ was $3.4 \pm 4 \%$, in control and 5.5 $\pm 2 \%$ in HFD mice, respectively (Fig. 4 ).

High fat diet induces changes in the pattern of cytokine synthesis by iIELs

To determine the possible effect of HFD on mRNA levels of different cytokines (IL-2, IL-15, TGF- $\beta$, TNF- $\alpha$, IFN- $\gamma$ ) and cytotoxic molecules produced by iIELs, the mRNAs levels were

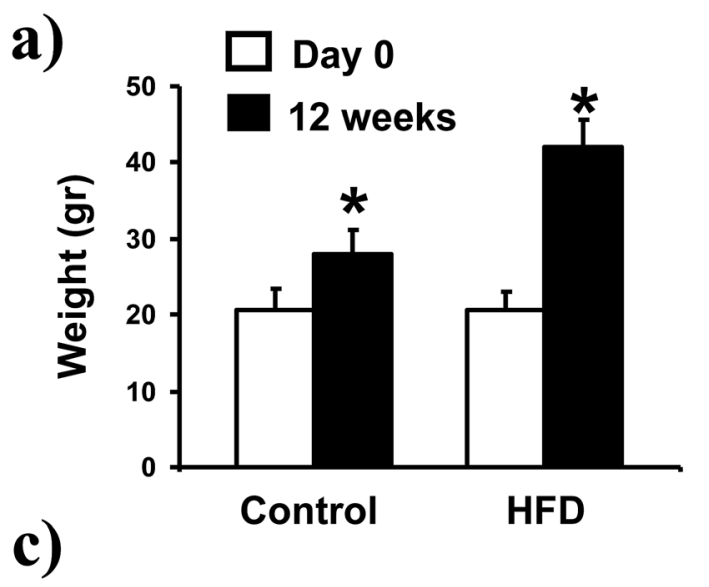

b)
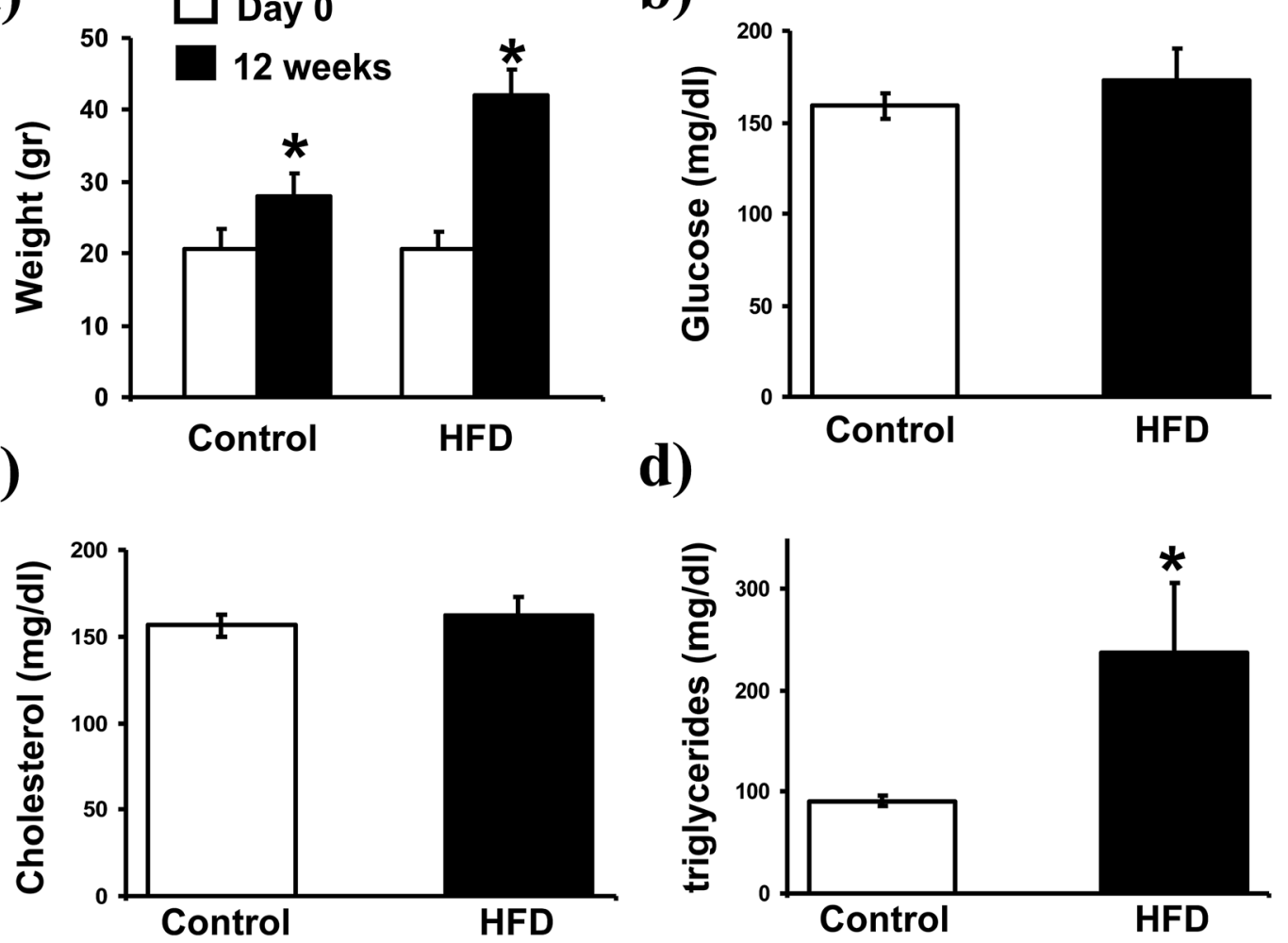

Fig. 1 Body weight gain and glucose, cholesterol, triglycerides levels on plasma. The body weight gain of each mouse was assessed and recorded at day 0 and 12 weeks of the experiment; graph bars in (a) represent the arithmetic mean \pm SD of weight in grams ( $\mathrm{g}$ ) of 10 mice. Blood samples were obtained from the retro-ocular plexus to determine glucose, cholesterol, and triglycerides levels with an Accutrend GCT system. The bars in the histograms represent the arithmetic mean \pm SD of glucose (b), cholesterol (c) and triglyceride (d) in mg $\mathrm{dL}^{-1}$ of $10 \mathrm{mice}$. ${ }^{*} p<0.05$ by U Mann Whitney. 
a)

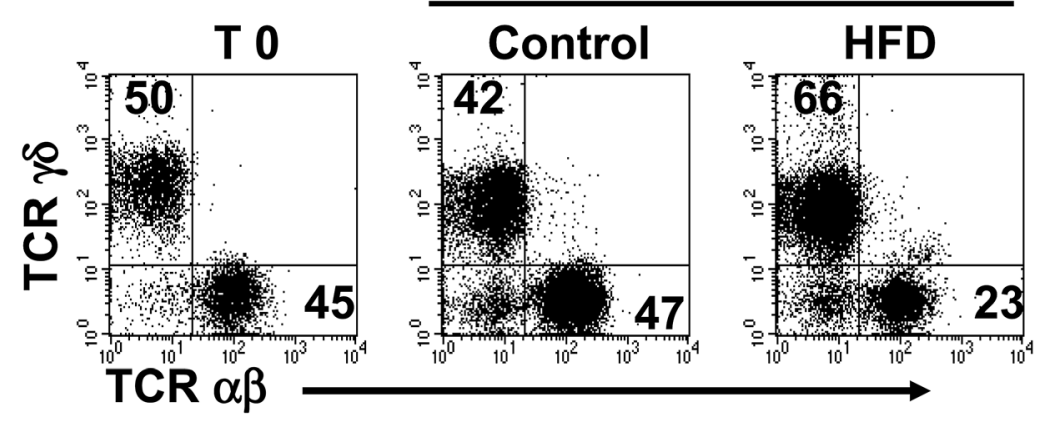

b)

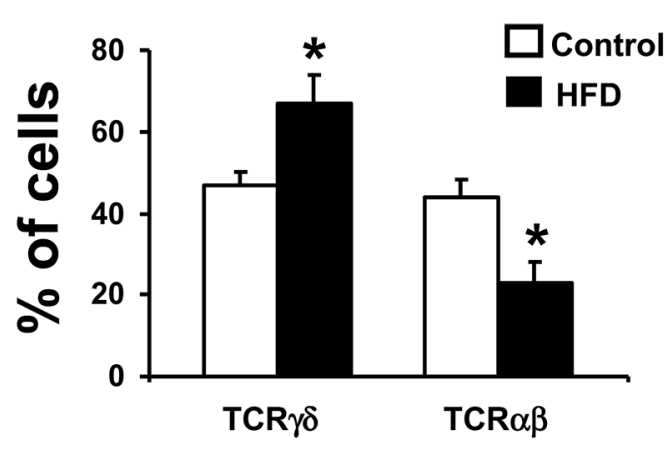

Fig. $2 \mathrm{TCR} \gamma \delta$ and TCR $\alpha \beta$ expressing cells in the small intestine of control and HFD feed mice. Freshly isolated ilELs were stained with anti TCR $\gamma \delta$, and TCR $\alpha \beta$ monoclonal antibodies and analyzed by flow cytometry. (a) Left panel correspond to representative flow cytometry dot plot of TCR $\gamma \delta$ and TCR $\alpha \beta$ expression on day 0 , and middle and right panels correspond to 12 weeks of control and HFD mouse, respectively. (b) HFD induced a significant increase in the proportion of TCR $\gamma \delta$ ilELs, and a significant decrease on TCR $\alpha \beta$ ilELs. Results are the mean \pm SD of 10 mice in each group, * $p<0.05$ compared with control mice by $\cup$ Mann Whitney.

a)

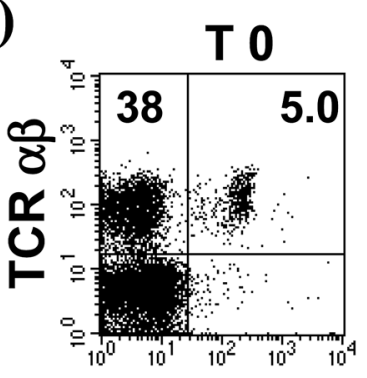

b)

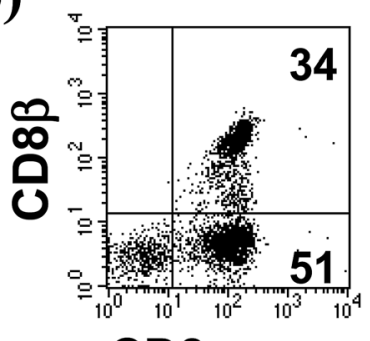

After 12 weeks
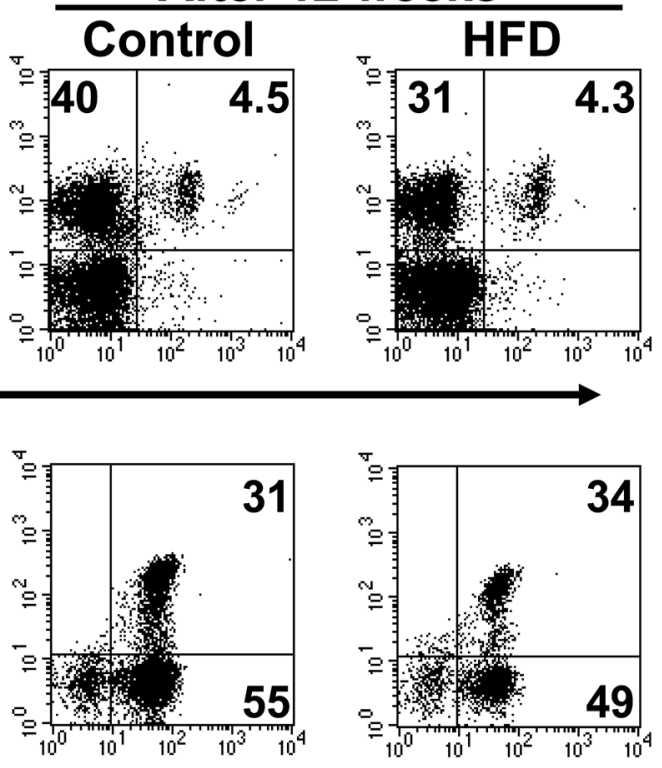

CD8 $\alpha$

Fig. 3 Subsets on TCR $\alpha \beta^{+}$expressing cells in the small intestine of control and HFD feed mice. Freshly isolated ilELs were stained with anti $\mathrm{TCR} \gamma \delta, T C R \alpha \beta, \mathrm{CD} 8 \alpha$ and $\mathrm{CD} 8 \beta$ monoclonal antibodies and analyzed by flow cytometry. (a) Correspond to representative flow cytometry dot plot of TCR $\alpha \beta^{+} C D 4^{+}$expression on day 0 (left panel), and middle and right panels correspond to 12 weeks of control and HFD mice, respectively. (b) Correspond to representative flow cytometry dot plot of CD $8 \alpha$ and CD $8 \beta$ expression ilELs gated on TCR $\alpha \beta^{+}$cells on day 0 (left panel), and middle and right panels correspond to 12 weeks of control and HFD mice, respectively. 


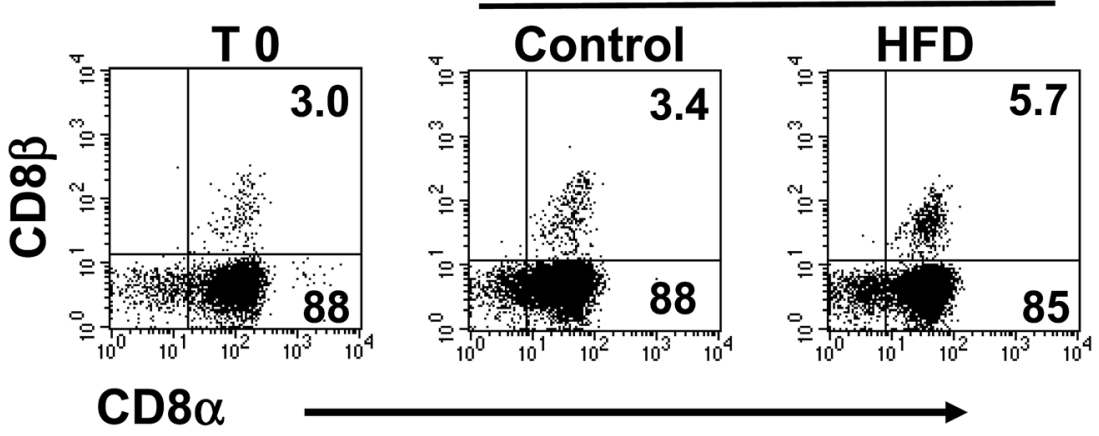

Fig. 4 Subsets on TCR $\delta \gamma^{+}$expressing cells in the small intestine of control and HFD feed mice. Freshly isolated ilELs were stained with anti $\mathrm{TCR} \gamma \delta, \mathrm{TCR} \alpha \beta, \mathrm{CD} 8 \alpha$ and $\mathrm{CD} 8 \beta$ monoclonal antibodies and analyzed by flow cytometry. Left panel corresponds to representative flow cytometry dot plot of CD $8 \alpha$ and CD8 $\beta$ expression ilELs gated on TCR $\gamma \delta^{+}$cells on day 0 , and middle and right panels correspond to 12 weeks of control and HFD mice, respectively.

a)

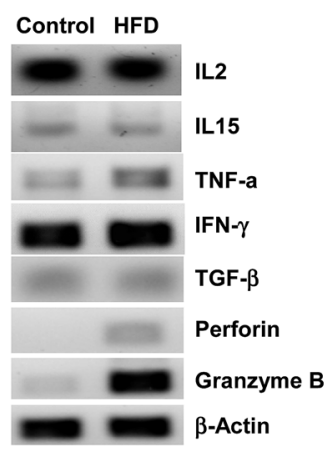

b)

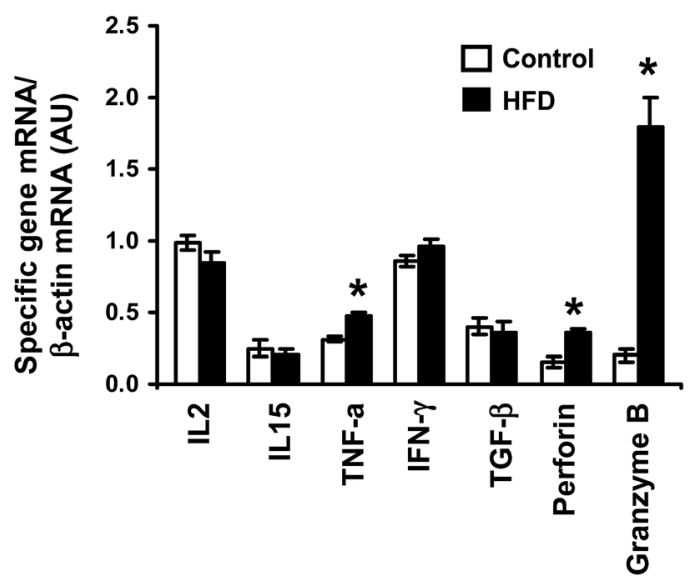

Fig. 5 Cytokines mRNA expression on total ilELs from ND and HFD feed mice. After 12 weeks of treatment, total RNA was isolated from ilELs from control and HFD mice, each mRNA sample was quantified and the levels of mRNA of IL2, IL15, TNF $\alpha$, IFN- $\gamma$, TGF- $\beta$, perforin and granzyme B were evaluated by conventional RT-PCR. The $\beta$-actin was used as internal control. (a) The PCR products were subjected to electrophoresis in $1.8 \%$ agarose gel, stained with ethidium bromide and visualized under UV light. (b) Quantitative real-time polymerase chain reactions (qRT-PCR) were performed using SYBR Green. RT-PCR results were normalized using $\beta$-actin as an internal control. Relative mRNA levels were calculated from the $C_{T}$ values for each sample and the ratios were reported as arbitrary units (AU). ${ }^{*} p<0.05$ compared with control mice by $U$ Mann Whitney.

assessed by both conventional and semiquantitative RT-PCR. We found that HFD did not induce changes on mRNA levels of IL2, IL15 nor TGF- $\beta$ (Fig. 5 a and b). In contrast, mRNA levels of TNF- $\alpha$ and perforin were significantly higher in HFD mice compared to control (Fig. 5b). Interestingly, a huge mRNA level of granzyme B was detected in HFD mice, whereas a slightly granzyme B mRNA level was observed in iIELs from control mice (Fig. $5 \mathrm{a}$ and $\mathrm{b}$ ). Although, high mRNA levels of IFN- $\gamma$ were observed in both HFD and control mice, no significant differences were detected between both groups (Fig. 5a and b).

\section{Discussion}

Intraepithelial lymphocytes are localized into the intestinal wall. To date there is not enough information about the mechanisms how iIELs protect the local cells from antigens and pathogenic micro-organisms; neither how cytokines produced by iIELs may regulate the local cellular functions and keep intestinal homeostasis.

It is well known, that consumption of a high fat diet (HFD) is associated with development of obesity in humans and animals. In mice, HFD induce disorders like those that occur in human, such as intestinal inflammation and insulin resistance. ${ }^{32}$ On the other hand, intestinal intraepithelial lymphocytes (iIELs) play an important role in the local immune response of the small intestine. iIELs are heterogeneous regarding to their phenotype, ontogeny, and functions. iIELs are organized in distinct subsets of $\mathrm{T}$ cells expressing either $\mathrm{TCR} \gamma \delta^{+}$or $\mathrm{TCR} \alpha \beta^{+}$, with potent cytolytic and immunoregulatory functions. However, the mechanisms and functions of both TCR $\gamma \delta^{+}$and TCR $\alpha \beta^{+}$iIELs have not been completely elucidated. Herein, we have determined the effect of HFD induced obesity on iIELs subsets in 
C57BL/6 mice. Our results clearly have shown that HFD induced a shift on proportion of $\operatorname{TCR} \gamma \delta^{+}$and TCR $\alpha \beta^{+}$within the iIELS population.

A recent report described that HFD promotes an important decrease in the proportion of iIELs and goblet cells, altering the secretion of hormones as well as maintenance of intestinal barrier; but the TCR $\gamma \delta^{+}$and TCR $\alpha \beta^{+}$iIELs subsets were no studied. ${ }^{34}$ Previous studies reported that different factors, such as pathogens and gut microbiota might change the proportions of iIELs. In this regard, infections with either S. typhimurium, $T$. gondii, or $N$. brasiliensis induced the expansion of iIELs expressing $\mathrm{TCR} \gamma \delta$; suggesting that $\mathrm{TCR} \gamma \delta$ contributed to maintain the integrity and function of intestinal epithelial tight junctions and goblet cells during infection..$^{33,35-37}$ Similarly, beneficial interactions between commensal microbiota and iIELs expressing TCR $\gamma \delta$ have been described. ${ }^{38,39}$

On the other hand, interactions between bacteria and HFD induced important changes in the gut microbiota ${ }^{\mathbf{1 0}}$ and a proinflammatory response in the small intestine on progression of obesity was triggered. ${ }^{32}$ Therefore, is clear that HFD induces changes on intestinal environment and iIELs might have an important role inducing local inflammation. However, so far there are few studies to elucidate the functions of iIELs in mice models of obesity.

In our experimental model of HFD induced obesity, the serum levels of cholesterol and glucose were similar between control and HFD mice; but an important increase on triglycerides and body weight was detected in HFD mice.

On this regards, different results on biochemical parameters have been published; some studies have shown that high fat diet increased blood levels of glucose, cholesterol, and triglycerides. ${ }^{40,41}$ Whereas de Sousa et al. have not observed changes on glucose and triglycerides, but an important increase on cholesterol was detected. ${ }^{42}$ Similarly, West et al. did not find any difference on glucose blood levels in several mice strains feed with HFD. ${ }^{43}$ Discordance on these results could be due to different fatty acid profile on diet formulation, ${ }^{\mathbf{4 2 , 4 4 , 4 5}}$ time of feeding mice, ${ }^{\mathbf{4 6 , 4 7}}$ and mouse strain used..$^{\mathbf{4 3 4 8}}$ Thus, the effect of HFD induced obesity on iIELs was associated firstly with HFD induced obesity and not by other biochemical changes such as high levels of glucose (linked to type 2 diabetes mellitus) or cholesterol (linked to cardiovascular disease).

Moreover, an increase on proportion of $\operatorname{TCR} \gamma \delta^{+}$and a decrease on TCR $\alpha \beta^{+}$within the iIELs population was found after 12 weeks of HFD. Previously, important changes in the proportions of bowel immune populations in the colon, including a reduced percentage of Tregs and an increase in IL17-producing $\gamma \delta \mathrm{T}$ cells, have been reported in mice feed with HFD. ${ }^{49}$ A similar effect was reported using dietary nucleotides, and this phenomenon was dependent of IL-7 produced by intestinal epithelial cells..$^{50}$

iIELs modulate important biological cellular functions by their cytotoxic activity and cytokines production on the small intestine. ${ }^{26}$ Here we have detected increased mRNA levels of TNF- $\alpha$, perforin, and granzyme B in iIELs from HFD mice. In this regard, a recent report described that in vivo stimulation with anti-CD3 monoclonal antibody activate $\operatorname{TCR} \gamma \delta$ to release granzyme $\mathrm{B}$, inducing DNA fragmentation on surrounding epithelial cells. ${ }^{51}$ In addition, a maximum cytotoxic activity of iIELs is preceded by perforin and granzyme B mRNA expression in ilELs after viral infection..$^{52}$ Additionally, we showed higher mRNA levels of TNF$\alpha$ in iIELs from HFD compared to control mice, suggesting that HFD promote the iIELs activation and synthesis of this cytokine. Consistently, previous reports have detected important changes on the levels of TNF- $\alpha$ mRNA after HFD feeding: ${ }^{34,53}$

Interestingly, HFD did not induce any change on mRNA levels of TGF- $\beta$, IL2 and IL15; cytokines that promote proliferation and protection of intestinal barrier. Therefore, it is possible that HFD induced damage on intestinal barrier and deregulation on iIELs functions, increasing mRNA levels of TNF- $\alpha$, perforin, and granzyme B. Previously, it has been described that HFD induced obesity is associated with alteration in occludin distribution and disruption of tight junctions of epithelial cells, a phenomenon that may result in an enhanced stimulation of iIELs and triggering an inflammatory event. ${ }^{11}$ Curiously, high levels of IFN- $\gamma$ mRNA were detected on iIELs of both groups, suggesting IFN- $\gamma$ is not modified by HFD, suggesting that IFN- $\gamma$ is mainly involved in specific immune response to intestinal damage induced by either bacteria or virus infection. ${ }^{\mathbf{5 4 - 5 6}}$

On the other hand, previous studies by DNA microarrays suggest that TCR $\gamma \delta^{+}$iIELs could participate in the intestinal lipid metabolism and cholesterol homeostasis. ${ }^{57}$ Thus, it is possible that increase of TCR $\gamma \delta^{+}$cells by HFD could be induced by different diet components to maintenance of a stable equilibrium through physiological processes; whereas, TCR $\alpha \beta^{+}$ iIELs may have a more restrictive role on these functions. Therefore, it may reflect selective functions of TCR $\alpha \beta^{+}$and TCR $\gamma \delta^{+}$subsets on the intestine compartment of HFD mice. Although, the functional differences among TCR $\alpha \beta^{+}$and $\operatorname{TCR} \gamma \delta^{+}$are still uncertain.

\section{Conclusions}

In summary, we have described that HFD induces important changes on proportion of iIELs as well as a significant increase on mRNA levels of TNF- $\alpha$, perforin, and granzyme B in whole iIELs population. These findings may provide important insights into intestinal changes produced on HFD induced obesity, which could eventually trigger intestinal inflammation. However, further investigations are required to elucidate the specific molecular mechanism of HFD induced changes on iIELs and cytokines mRNA; primarily, because diet formulation (fatty acid profile) may produce different effect in gut.

\section{Conflict of interest}

All authors declare no conflict of interest.

\section{Acknowledgements}

This work was supported by CONACYT (Grant number 79561) and DAIP, Universidad de Guanajuato (Grant number 000027/ 08). 


\section{References}

1 S. O'Rahilly and I. S. Farooqi, Human obesity as a heritable disorder of the central control of energy balance, Int. $J$. Obes., 2008, 32(suppl. 7), S55-S61.

2 I. S. Farooqi, Genetic, molecular and physiological insights into human obesity, Eur. J. Clin. Invest., 2011, 41, 451-455.

3 A. Bartolomucci, A. Cabassi, P. Govoni, G. Ceresini, C. Cero, D. Berra, H. Dadomo, P. Franceschini, G. Dell'Omo, S. Parmigiani and P. Palanza, Metabolic consequences and vulnerability to diet-induced obesity in male mice under chronic social stress, PLoS One, 2009, 4, e4331.

4 M. Munoz, R. A. Mazure and J. M. Culebras, Obesity and the immune system, Nutr. Hosp., 2004, 19, 319-324.

5 G. S. Hotamisligil, Inflammation and metabolic disorders, Nature, 2006, 444, 860-867.

6 H. Xu, G. T. Barnes, Q. Yang, G. Tan, D. Yang, C. J. Chou, J. Sole, A. Nichols, J. S. Ross, L. A. Tartaglia and H. Chen, Chronic inflammation in fat plays a crucial role in the development of obesity-related insulin resistance, J. Clin. Invest., 2003, 112, 1821-1830.

7 M. F. Gregor and G. S. Hotamisligil, Inflammatory mechanisms in obesity, Annu. Rev. Immunol., 2011, 29, 415-445.

8 A. Syrenicz, B. Garanty-Bogacka, M. Syrenicz, A. Gebala and M. Walczak, Low-grade systemic inflammation and the risk of type 2 diabetes in obese children and adolescents, Neuroendocrinol. Lett., 2006, 27, 453-458.

9 K. Karmiris, I. E. Koutroubakis and E. A. Kouroumalis, The emerging role of adipocytokines as inflammatory mediators in inflammatory bowel disease, Inflammatory Bowel Dis., 2005, 11, 847-855.

10 H. Li, C. Lelliott, P. Hakansson, K. Ploj, A. Tuneld, M. Verolin-Johansson, L. Benthem, B. Carlsson, L. Storlien and E. Michaelsson, Intestinal, adipose, and liver inflammation in diet-induced obese mice, Metabolism, 2008, 57, 1704-1710.

11 C. B. de La Serre, C. L. Ellis, J. Lee, A. L. Hartman, J. C. Rutledge and H. E. Raybould, Propensity to high-fat diet-induced obesity in rats is associated with changes in the gut microbiota and gut inflammation, Am. J. Physiol.: Gastrointest. Liver Physiol., 2010, 299, G440-G448.

12 T. Chardes, D. Buzoni-Gatel, A. Lepage, F. Bernard and D. Bout, Toxoplasma gondii oral infection induces specific cytotoxic CD8 alpha/beta ${ }^{+}$Thy- ${ }^{+}$gut intraepithelial lymphocytes, lytic for parasite-infected enterocytes, $J$. Immunol., 1994, 153, 4596-4603.

$13 \mathrm{~K}$. W. Beagley and A. J. Husband, Intraepithelial lymphocytes: origins, distribution, and function, Crit. Rev. Immunol., 1998, 18, 237-254.

14 H. Kiyono, K. Fujihashi, T. Taguchi, W. K. Aicher and J. R. McGhee, Regulatory functions for murine intraepithelial lymphocytes in mucosal responses, Immunol. Res., 1991, 10, 324-330.

15 K. Fujihashi, T. Taguchi, J. R. McGhee, J. H. Eldridge, M. G. Bruce, D. R. Green, B. Singh and H. Kiyono,
Regulatory function for murine intraepithelial lymphocytes. Two subsets of $\mathrm{CD}^{+}, \mathrm{T}$ cell receptor $-1^{+}$ intraepithelial lymphocyte $\mathrm{T}$ cells abrogate oral tolerance, J. Immunol., 1990, 145, 2010-2019.

16 Y. Fujiura, M. Kawaguchi, Y. Kondo, S. Obana, H. Yamamoto, M. Nanno and H. Ishikawa, Development of CD8 alphaalpha ${ }^{+}$intestinal intraepithelial $\mathrm{T}$ cells in beta 2microglobulin- and/or TAP1-deficient mice, J. Immunol., 1996, 156, 2710-2715.

17 B. S. Podd, C. Aberg, T. L. Christopher, F. Perez-Cano and V. Camerini, Late postnatal expansion of self-reactive CD8 alphaalpha $^{+}$intestinal intraepithelial lymphocytes in mice, Autoimmunity, 2004, 37, 537-547.

18 B. C. Sydora, L. Brossay, A. Hagenbaugh, M. Kronenberg and H. Cheroutre, TAP-independent selection of $\mathrm{CD} 8^{+}$intestinal intraepithelial lymphocytes, J. Immunol., 1996, 156, 42094216.

19 L. Gapin, H. Cheroutre and M. Kronenberg, Cutting edge: TCR alphabeta ${ }^{+}$CD8 alphaalpha ${ }^{+} \mathrm{T}$ cells are found in intestinal intraepithelial lymphocytes of mice that lack classical MHC class I molecules, J. Immunol., 1999, 163, 4100-4104.

20 M. Ogimoto, G. Matsuzaki, Y. Yoshikai, Y. Tauchi and K. Nomoto, Appearance of TCR-alphabeta ${ }^{+} \mathrm{CD} 4^{-} \mathrm{CD} 8^{-}$skin intraepithelial lymphocytes in radiation bone marrow chimeras, J. Immunol., 1993, 151, 3000-3006.

21 R. L. Mosley, D. Styre and J. R. Klein, $\mathrm{CD}^{+} \mathrm{CD} 8^{+}$murine intestinal intraepithelial lymphocytes, Int. Immunol., 1990, 2, 361-365.

22 T. Sasahara, H. Tamauchi, N. Ikewaki and K. Kubota, Unique properties of a cytotoxic $\mathrm{CD} 4{ }^{+} \mathrm{CD}^{+}{ }^{+}$intraepithelial T-cell line established from the mouse intestinal epithelium, Microbiol. Immunol., 1994, 38, 191-199.

23 O. Neuhaus, M. Emoto, C. Blum, S. Yamamoto and S. H. Kaufmann, Control of thymus-independent intestinal intraepithelial lymphocytes by beta 2-microglobulin, Eur. J. Immunol., 1995, 25, 2332-2339.

24 G. Das and C. A. Janeway Jr, Development of CD8 alpha/ alpha and CD8 alpha/beta $\mathrm{T}$ cells in major histocompatibility complex class I-deficient mice, J. Exp. Med., 1999, 190, 881-884.

25 S. H. Park, D. Guy-Grand, F. A. Lemonnier, C. R. Wang, A. Bendelac and B. Jabri, Selection and expansion of CD8 alpha/alpha(1) $\mathrm{T}$ cell receptor alpha/beta(1) intestinal intraepithelial lymphocytes in the absence of both classical major histocompatibility complex class I and nonclassical CD1 molecules, J. Exp. Med., 1999, 190, 885-890.

26 Y. Qiu and H. Yang, Effects of intraepithelial lymphocytederived cytokines on intestinal mucosal barrier function, $J$. Interferon Cytokine Res., 2013, 33, 551-562.

27 J. J. Cebra, S. B. Periwal, G. Lee, F. Lee and K. E. Shroff, Development and maintenance of the gut-associated lymphoid tissue (GALT): the roles of enteric bacteria and viruses, Dev. Immunol., 1998, 6, 13-18.

28 C. M. Galdeano and G. Perdigon, The probiotic bacterium Lactobacillus casei induces activation of the gut mucosal 
immune system through innate immunity, Clin. Vaccine Immunol., 2006, 13, 219-226.

29 B. C. Sydora, B. D. Jamieson, R. Ahmed and M. Kronenberg, Intestinal intraepithelial lymphocytes respond to systemic lymphocytic choriomeningitis virus infection, Cell. Immunol., 1996, 167, 161-169.

30 M. Kaneko, T. Mizunuma, H. Takimoto and Y. Kumazawa, Development of TCR alphabeta CD8 alphaalpha intestinal intraepithelial lymphocytes is promoted by interleukin-15producing epithelial cells constitutively stimulated by Gram-negative bacteria via TLR4, Biol. Pharm. Bull., 2004, 27, 883-889.

31 D. Bruce and M. T. Cantorna, Intrinsic requirement for the vitamin D receptor in the development of CD8alphaalphaexpressing T cells, J. Immunol., 2011, 186, 2819-2825.

32 S. Ding, M. M. Chi, B. P. Scull, R. Rigby, N. M. Schwerbrock, S. Magness, C. Jobin and P. K. Lund, High-fat diet: bacteria interactions promote intestinal inflammation which precedes and correlates with obesity and insulin resistance in mouse, PLoS One, 2010, 5, e12191.

33 A. Davies, S. Lopez-Briones, H. Ong, C. O'Neil-Marshall, F. A. Lemonnier, K. Nagaraju, E. S. Metcalf and M. J. Soloski, Infection-induced expansion of a MHC Class Ib-dependent intestinal intraepithelial gammadelta $\mathrm{T}$ cell subset, J. Immunol., 2004, 172, 6828-6837.

34 A. Soares, E. J. Beraldi, P. E. Ferreira, R. B. Bazotte and N. C. Buttow, Intestinal and neuronal myenteric adaptations in the small intestine induced by a high-fat diet in mice, BMC Gastroenterol., 2015, 15, 3.

35 J. E. Dalton, S. M. Cruickshank, C. E. Egan, R. Mears, D. J. Newton, E. M. Andrew, B. Lawrence, G. Howell, K. J. Else, M. J. Gubbels, B. Striepen, J. E. Smith, S. J. White and S. R. Carding, Intraepithelial gammadelta ${ }^{+}$ lymphocytes maintain the integrity of intestinal epithelial tight junctions in response to infection, Gastroenterology, 2006, 131, 818-829.

36 Z. Li, C. Zhang, Z. Zhou, J. Zhang, J. Zhang and Z. Tian, Small intestinal intraepithelial lymphocytes expressing CD8 and T cell receptor gammadelta are involved in bacterial clearance during Salmonella enterica serovar Typhimurium infection, Infect. Immun., 2012, 80, 565-574.

37 K. Inagaki-Ohara, Y. Sakamoto, T. Dohi and A. L. Smith, gammadelta $\mathrm{T}$ cells play a protective role during infection with Nippostrongylus brasiliensis by promoting goblet cell function in the small intestine, Immunology, 2011, 134, 448-458.

38 A. S. Ismail, C. L. Behrendt and L. V. Hooper, Reciprocal interactions between commensal bacteria and gamma delta intraepithelial lymphocytes during mucosal injury, $J$. Immunol., 2009, 182, 3047-3054.

39 A. S. Ismail, K. M. Severson, S. Vaishnava, C. L. Behrendt, X. Yu, J. L. Benjamin, K. A. Ruhn, B. Hou, A. L. DeFranco, F. Yarovinsky and L. V. Hooper, Gammadelta intraepithelial lymphocytes are essential mediators of hostmicrobial homeostasis at the intestinal mucosal surface, Proc. Natl. Acad. Sci. U. S. A., 2011, 108, 8743-8748.
40 P. R. de Oliveira, C. A. da Costa, G. F. de Bem, L. C. de Cavalho, M. A. de Souza, M. de Lemos Neto, P. J. da Cunha Sousa, R. S. de Moura and A. C. Resende, Effects of an extract obtained from fruits of Euterpe oleracea Mart. in the components of metabolic syndrome induced in C57BL/ $6 \mathrm{~J}$ mice fed a high-fat diet, J. Cardiovasc. Pharmacol., 2010, 56, 619-626.

41 L. McAllan, P. Skuse, P. D. Cotter, P. O'Connor, J. F. Cryan, R. P. Ross, G. Fitzgerald, H. M. Roche and K. N. Nilaweera, Protein quality and the protein to carbohydrate ratio within a high fat diet influences energy balance and the gut microbiota in C57BL/6J mice, PLoS One, 2014, 9, e88904.

42 M. E. de Sousa Rodrigues, M. Bekhbat, M. C. Houser, J. Chang, D. I. Walker, D. P. Jones, C. M. Oller do Nascimento, C. J. Barnum and M. G. Tansey, Chronic psychological stress and high-fat high-fructose diet disrupt metabolic and inflammatory gene networks in the brain, liver, and gut and promote behavioral deficits in mice, Brain, Behav., Immun., 2017, 59, 158-172.

43 D. B. West, C. N. Boozer, D. L. Moody and R. L. Atkinson, Dietary obesity in nine inbred mouse strains, Am. J. Physiol., 1992, 262, R1025-R1032.

44 B. Ojo, G. D. El-Rassi, M. E. Payton, P. Perkins-Veazie, S. Clarke, B. J. Smith and E. A. Lucas, Mango Supplementation Modulates Gut Microbial Dysbiosis and Short-Chain Fatty Acid Production Independent of Body Weight Reduction in C57BL/6 Mice Fed a High-Fat Diet, J. Nutr., 2016, 146, 1483-1491.

45 J. B. Holm, A. Ronnevik, H. S. Tastesen, E. Fjaere, K. R. Fauske, U. Liisberg, L. Madsen, K. Kristiansen and B. Liaset, Diet-induced obesity, energy metabolism and gut microbiota in $\mathrm{C} 57 \mathrm{BL} / 6 \mathrm{~J}$ mice fed Western diets based on lean seafood or lean meat mixtures, J. Nutr. Biochem., 2016, 31, 127-136.

46 P. S. Daltro, P. S. Alves, M. F. Castro, C. M. Azevedo, J. F. Vasconcelos, K. J. Allahdadi, L. A. de Freitas, B. S. de Freitas Souza, R. R. Dos Santos, M. B. Soares and S. G. Macambira, Administration of granulocyte-colony stimulating factor accompanied with a balanced diet improves cardiac function alterations induced by high fat diet in mice, BMC Cardiovasc. Disord., 2015, 15, 162.

47 L. W. Engstrom, L. Bober, S. C. Chen, J. S. Fine, Y. Li, M. C. Stanton, D. Kinsley, L. Cui, J. V. Jackson, A. RojasTriana, D. Lundell, M. Laverty, E. L. Gustafson, C. H. Jenh, T. J. Kowalski and D. J. Manfra, Kinetic assessment and therapeutic modulation of metabolic and inflammatory profiles in mice on a high-fat and cholesterol diet, PPAR Res., 2010, 2010, 970164.

48 T. H. Ehrich, J. P. Kenney, T. T. Vaughn, L. S. Pletscher and J. M. Cheverud, Diet, obesity, and hyperglycemia in LG/J and SM/J mice, Obes. Res., 2003, 11, 1400-1410.

49 H. Luck, S. Tsai, J. Chung, X. Clemente-Casares, M. Ghazarian, X. S. Revelo, H. Lei, C. T. Luk, S. Y. Shi, A. Surendra, J. K. Copeland, J. Ahn, D. Prescott, B. A. Rasmussen, M. H. Chng, E. G. Engleman, S. E. Girardin, T. K. Lam, K. Croitoru, S. Dunn, D. J. Philpott, D. S. Guttman, M. Woo, S. Winer and 
D. A. Winer, Regulation of obesity-related insulin resistance with gut anti-inflammatory agents, Cell Metab., 2015, 21, 527-542.

50 S. Nagafuchi, M. Totsuka, S. Hachimura, M. Goto, T. Takahashi, T. Yajima, T. Kuwata and S. Kaminogawa, Dietary nucleotides increase the proportion of a TCR gammadelta $^{+}$subset of intraepithelial lymphocytes (IEL) and IL-7 production by intestinal epithelial cells (IEC); implications for modification of cellular and molecular cross-talk between IEL and IEC by dietary nucleotides, Biosci., Biotechnol., Biochem., 2000, 64, 1459-1465.

51 M. Ogata, Y. Ota, M. Nanno, R. Suzuki and T. Itoh, Autocrine DNA fragmentation of intra-epithelial lymphocytes (IELs) in mouse small intestine, Cell Tissue Res., 2015, 361, 799-810.

52 S. Muller, M. Buhler-Jungo and C. Mueller, Intestinal intraepithelial lymphocytes exert potent protective cytotoxic activity during an acute virus infection, $J$. Immunol., 2000, 164, 1986-1994.

53 Z. Liu, R. S. Brooks, E. D. Ciappio, S. J. Kim, J. W. Crott, G. Bennett, A. S. Greenberg and J. B. Mason, Diet-induced obesity elevates colonic TNF-alpha in mice and is accompanied by an activation of Wnt signaling: a mechanism for obesity-associated colorectal cancer, $J$. Nutr. Biochem., 2012, 23, 1207-1213.

54 X. Luo, S. Luo, Y. Zheng, R. Wen, X. Deng and L. Zhou, Intestinal dysbacteriosis promotes intestinal intraepithelial $\mathrm{T}$ lymphocyte activation and proinflammatory cytokine secretion in mice, Xibao Yu Fenzi Mianyixue Zazhi, 2016, 32, 1031-1035.

55 S. Yamamoto, F. Russ, H. C. Teixeira, P. Conradt and S. H. Kaufmann, Listeria monocytogenes-induced gamma interferon secretion by intestinal intraepithelial gamma/ delta T lymphocytes, Infect. Immun., 1993, 61, 2154-2161.

56 M. Swamy, L. Abeler-Dorner, J. Chettle, T. Mahlakoiv, D. Goubau, P. Chakravarty, G. Ramsay, C. Reis e Sousa, P. Staeheli, B. A. Blacklaws, J. L. Heeney and A. C. Hayday, Intestinal intraepithelial lymphocyte activation promotes innate antiviral resistance, Nat. Commun., 2015, 6, 7090.

57 A. M. Fahrer, Y. Konigshofer, E. M. Kerr, G. Ghandour, D. H. Mack, M. M. Davis and Y. H. Chien, Attributes of gammadelta intraepithelial lymphocytes as suggested by their transcriptional profile, Proc. Natl. Acad. Sci. U. S. A., 2001, 98, 10261-10266. 